Çukurova Üniversitesi Mühendislik Mimarlık Fakültesi Dergisi, 31(1), 11-21 ss., Haziran 2016

Çukurova University Journal of the Faculty of Engineering and Architecture, 31(1), pp. 11-21 , June 2016

\title{
Karbon Lifli Polimer Sargılı Narin Betonarme Kolonların Moment Büyütme Yöntemi ile Analizi
}

\author{
Duygu ERTÜRKMEN"1, Cengiz DÜNDAR ${ }^{1}$, Serkan TOKGÖZ² \\ ${ }^{1}$ Çukurova Üniversitesi, Mühendislik Mimarlık Fakültesi, İnşaat Mühendisliği Bölümü, Adana \\ ${ }^{2}$ Mersin Üniversitesi, Mühendislik Fakültesi, İnşaat Mühendisliği Bölümü, Mersin
}

Geliş tarihi: 02.12 .2015

Kabul tarihi: 07.03.2016

\section{Özet}

Bu çalışmada, karbon lifli polimer sargılı yüksek dayanımlı çelik lifli ve lifsiz betonarme kolonların davranışları incelenmiştir. Bu amaçla hazırlanan 8 adet çelik lifli ve lifsiz karbon fiber sargılı betonarme kolon numuneler iki eksenli eğilme ve eksenel yük altında test edilerek taşıma gücü kapasiteleri ve yükdeplasman eğrileri belirlenmiş ve aynı kolon numunelerinin teorik olarak da analizi gerçekleştirilmiştir. Analizde beton basınç bölgesi için literatürde yer alan sargılı beton gerilme-şekil değiştirme modeli kullanılmıştır. Ele alınan kolon numunelerin beton basınç dayanımı 53,13 76,76 MPa arasında değişmektedir. Test edilen kolon numunelerine ait dayanım, dış merkezlik, karbon lifli polimer malzeme özellikleri ve narinlik etkisi parametreleri yapılan analizlerde incelenmiştir. Analizde, narinlik etkisi ACI-318 yönetmeliği tarafından önerilen Moment Büyütme Yöntemi' ne göre ele alınmıştır. Kolon numunelerin analizinden elde edilen sonuçların deneysel olarak elde edilen sonuçlarla uyum içinde olduğu gözlenmiştir.

Anahtar Kelimeler: Süneklik, Çelik lifli beton, Karbon lifli polimer, Sargılı beton, İki eksenli eğilme

\section{Analysis of Carbon Fiber Polymer Confined Slender Reinforced Concrete Columns by Using Moment Magnification Method}

\begin{abstract}
In this study, the behavior of carbon fiber polymer confined plain and steel fiber reinforced concrete columns were examined. For this purpose, carbon fiber polymer confined plain and steel fiber reinforced concrete column specimens were prepared and analyzed to determine the ultimate strength capacity and the load-deflection curves of columns. In the analysis, a stress-strain model for confined concrete was used for the concrete compression zone. Compressive strength of reinforced concrete column specimens are range from 53,13 76,76 $\mathrm{MPa}$. In the analysis compressive strength, eccentricity, carbon fiber polymer
\end{abstract}

* Yazışmaların yapılacağı yazar: Duygu ERTÜRKMEN, Mühendislik Mimarlık Fakültesi, İnşaat Mühendisliği Bölümü, Adana.dbasli@cu.edu.tr 
material properties and parameters of slenderness effect were examined. In the analysis, slenderness effect of the column is taken into account by using Moment Magnification Method suggested by ACI-318 building code requirements for structural concrete. In conclusion the analysis and experimental results of carbon fiber reinforced polymer confined plain and steel fiber reinforced concrete columns have been achieved in good accuracy.

Keywords: Ductility, Steel fiber concrete, Carbon fiber polymer, Confined concrete, Biaxial bending

\section{GíRiş}

Betonarme yapılarda düşey elemanlardan olan kolonlar, yapının dayanımı ve taşıma kapasitesi bakımından önemli elemanlardır. Söz konusu elemanlar yüksek dayanımlı beton ile de üretilebilmektedir. Ancak yüksek dayanımlı beton gevrek davranış gösterdiğinden bu şekilde hazırlanan kolonlar maksimum taşıma kapasitelerine ulaştığında ani olarak kırılmaktadır. $\mathrm{Bu}$ tür kolonların süneklik düzeyini arttırmak için beton içerisine belirli oranda çelik lif katılmaktadır. Bunların yanında, taşıma gücü kapasitesini ve sarg1 etkisini daha da arttırmak amacıyla kolonlar karbon lifli polimer malzeme (CFRP) ile dıştan sarılmaktadır. Böylece betonarme bir kolonla kıyaslandığında aynı özellikteki karbon lifli polimer malzeme sargilı kolonun taşıma gücü kapasitesi ve sünekliği, önemli düzeyde artış göstermektedir.

CFRP malzemesi betonarme elemanlara oldukça kolay ve hızlı bir şekilde uygulanabilmektedir. CFRP malzemesinin mekanik özellikleri, türü, elastisite modülü, dayanımı, kalınlığı, elemana uygulanan kat sayısı, malzemedeki liflerin yerleşimi ve yönü, CFRP sargılı elemanların yapısal davranışlarını büyük ölçüde etkilemekte ve değiştirmektedir.

Bilindiği gibi betonarme yapılarda genellikle köşe kolonlar düşey yükler, rüzgar yükleri veya deprem yükleri nedeniyle eksantrik yüklemelere maruz kalabilmektedir [1]. Gerek CFRP malzemesi ile sarılı eksantrik yüklü narin betonarme kolonların davranışlarının belirlenmesine gerekse lifli polimer sargılı betonarme elemanların mekanik davranışlarının belirlenmesine ilişkin pek çok sayıda teorik ve deneysel araştırma yapılmıştır. Mirmiran ve Shahawy (1997), Toutanji ve Balaguru (1998), Teng ve Lam (2002), lifli polimer malzeme ile sarılı kolonların yapısal davranışları üzerinde çalışmışlardır [2-4]. Samaan ve arkadaşları (1998), ekseni doğrultusunda ve yanal yönde lifli polimer sargılı betonarme elemanların davranışlarının belirlenmesi için bir sarg1 modeli önermişlerdir [5]. Hadi (2006), lifli polimer malzeme ile sarılı normal dayanımlı betonarme kolonların eksantrik yük etkisindeki davranışlarının belirlenmesi için deneysel bir çalışma gerçekleştirmiştir. Elde ettiği deneysel sonuçlara göre lifli polimer malzeme ile sarılı betonarme kolonların daha yüksek dayanım, süneklik ve enerji yutma kapasitesi özelliklerine sahip olduğunu gözlemlemiştir [6]. Zaki (2011), karbon lifli polimer malzeme kullanılarak güçlendirilmiş eksantrik yüklü betonarme kolonlara ilişskin bir analiz ve tasarım yöntemi önermiştir [7]. Vincent ve Özbakkaloğlu (2013), lifli polimer sargı malzemesindeki liflerin dağılım ve yönlerinin betonarme kolonların davranışına olan etkilerini incelemişlerdir. Ayrıca sargılı betonarme kolonların sarılmasının kolonun basınç altındaki davranışına olan etkilerini araştırmışlardır [8]. Punurai, Hsu ve arkadaşları (2013), iki eksenli eğilmeye maruz karbon lifli polimer malzeme ile kaplı narin betonarme kolonların deneysel ve teorik davranışlarını incelemişlerdir [9].

Literatürde karbon lifli polimer sargılı çelik lifli narin betonarme kolonların davranışlarını konu alan çalışmalar oldukça sınırlı kalmıştır. Sunulan çalışmada, karbon lifli polimer sargılı çelik lifli ve lifsiz yüksek dayanımlı betonarme kolanların davranışının belirlenmesi amacıyla yapılan deneysel çalışmaya ek olarak bir de analiz çalışması gerçekleştirilmiştir. Analizde, narinlik etkisi ACI-318 yönetmeliğinde önerilen Moment Büyütme Yöntemi' ne göre ele alınmıştır. 
Analizlerde beton basınç bölgesi için literatürde yer alan karbon lifli sargılı ve sargısız çelik lifli ve lifsiz beton davranışını tanımlayan gerilme-şekil değiştirme modelleri kullanılmıştır. Analizler sonucunda elde edilen kolon taşıma gücü kapasitesi değerlerinin deneysel olarak elde edilen değerlerle uyumlu olduğu belirlenmiştir.

\section{MATERYAL VE METOT}

\subsection{Materyal}

Sunulan çalışmada, çelik lifsiz ve lifli, sargısız ve karbon lifli sargilı olarak tasarlanan 8 adet kolon numunenin iki eksenli eğilme ve eksenel basınç altındaki davranışını simgeleyen sonuçlar, deneysel ve analitik olarak verilmiştir.

Test edilen kolon numunelerinin hazırlanmasında iki farklı beton karışımı kullanılmıştır. İlk beton karışımı C1, ikinci beton karışımı C2 serisi olarak adlandırılmış ve çelik lif ilave edilen serilere çelik lif katkısını simgeleyen SF kısaltması eklenmiştir. C1 serisi çelik lif kullanılmayan seri olup C1-0 sargısız, C1-II çift kat CFRP sargılı numunelerdir. C1-SF serisi bunların çelik lif katkılı olanları olup yine C1-0-SF sargisız, C1-II-SF çift kat CFRP sargılı numunelerdir. İkinci beton karışımı olan $\mathrm{C} 2$ serisi ve C2-SF serisi içinde C2-0 sargısı, C2-II çift kat sarg1l1, C2-0-SF sarg1sız ve C2-II-SF yine çift kat sargilı olan numunelerdir. Belirtilen serilerde yer alan numuneler için $1 \mathrm{~m}^{3}$ hacimde kullanılan beton karışım oranları Çizelge 1'de görülmektedir. Söz konusu numunelerde sargılı ve sargısız silindir basınç dayanımı değerleri 53,13 76,76 MPa aralığında elde edilmiştir.

Çizelge 1. Numunelere ait beton karışım oranları

\begin{tabular}{lccccc}
\multicolumn{7}{c}{$\left(1 \mathrm{~m}^{3}\right.$ hacim için $)$} \\
\hline Malzeme & $\mathrm{C} 1$ & $\mathrm{C} 1-\mathrm{SF}$ & $\mathrm{C} 2$ & $\mathrm{C} 2-\mathrm{SF}$ \\
\hline Çakıl $(\mathrm{kg})$ & 1120 & 1110 & 1100 & 1090 \\
Kum $(\mathrm{kg})$ & 725 & 720 & 640 & 630 \\
Çimento $(\mathrm{kg})$ & 400 & 400 & 400 & 400 \\
Su $(1)$ & 150 & 150 & 120 & 120 \\
Kimyasal $(\mathrm{kg})$ & 5 & 5 & 15 & 15 \\
Lif $(\mathrm{kg})$ & - & 50 & - & 60 \\
\hline Hażrlanan & kolon & numuneler & \multicolumn{2}{c}{1300} & $\mathrm{~mm}$ \\
uzunluğunda & ve & $125 \times 125$ & $\mathrm{~mm}$ & \multicolumn{2}{c}{ kesitinde }
\end{tabular}

tasarlanmıştır. Kolon numunelerde gerek iki eksenli eğilme ve eksenel basıncı sağlamak gerekse kolon uçlarında oluşabilecek yerel kırılmaları önlemek üzere numunelerin iki ucunda $200 \times 200 \mathrm{~mm}$ başlık oluşturulmuştur. Kolon köşelerinde $8 \mathrm{~mm}$ çapında, akma dayanımı $550 \mathrm{MPa}$ olan boyuna donatı kullanılmıştır. $6 \mathrm{~mm}$ çapındaki akma dayanımı $630 \mathrm{MPa}$ olan etriyeler, kolon boyunca $100 \mathrm{~mm}$ aralıklarla yerleştirilmiştir. Kolon numunelerine ait detaylar Şekil 1'de verilmiştir.

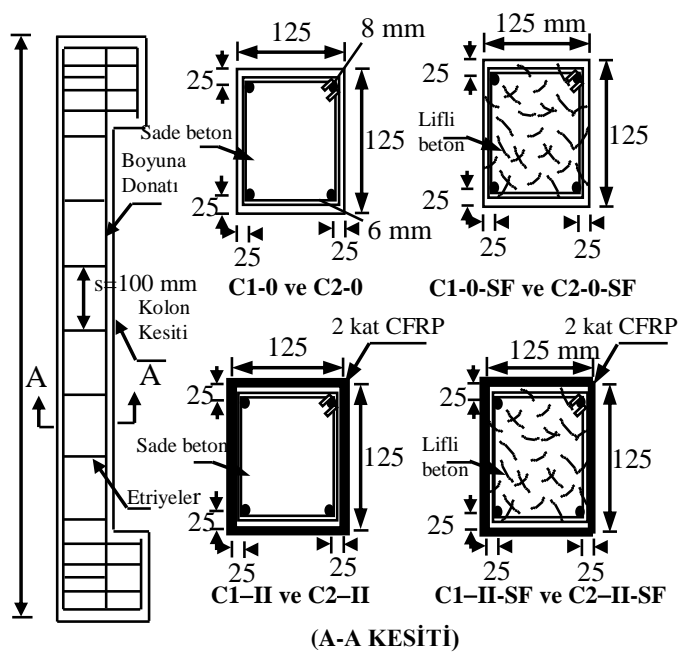

Şekil 1. Sargılı ve sargısız kolon numunelerine ait kesit detayları ve donatı düzeni

Numunelere ait beton karışımlarında PÇ42,5 dayanımlı çimento, maksimum dane boyutu $20 \mathrm{~mm}$ olan agrega malzemesi ve RC 65/35 BN kodlu çelik lif kullanılmıştır. Numuneler prizlerini aldıktan sonra çift yönlü lif içeren Sika Wrap Hex 300C 0/90 olarak adlandırılan karbon lifli polimer malzeme ile Sikadur-330 isimli epoksi yapıştırıcısı kullanılarak sarılmıştır. CFRP sargılı ve sargısız olarak hazırlanan deney numunelerine ait örnekler Şekil 2'de görülmektedir.

Karbon lifli polimer sargısının kolonların davranışları üzerindeki etkilerinin belirlenmesi için hazırlanan 8 numuneden dört tanesi çift kat malzeme kullanılarak sarılmıştır. 



Şekil 2. Sargılı ve sargısız kolon numune örnekleri

Kalan dört tanesi ise sargı yapılmayan lifsiz ve lifli beton karışımları ile imal edilen referans numuneleridir. Numunelere ait basınç dayanımı değerleri, numuneler hazırlanırken alınmış olan silindir numune örneklerinin numunelerin test edildiği gün içerisinde eksenel basınç altında denenmesi ile elde edilmiştir. Numune isimleri, numunelere ait beton basınç dayanımı değerleri, deneylerde numunelere uygulanan yükün eksantrisite değerleri ve numune hazırlığında kullanılan sarg1 miktarı bilgileri Çizelge 2'de verilmiştir.

Çizelge 2. Numunelere ait dayanım ve eksantrisite değerleri ile kullanılan CFRP sarg1 miktar1

\begin{tabular}{lccc}
\hline Numune & $\begin{array}{c}\mathrm{f}_{\mathrm{cd}} \\
\left(\mathrm{kN} / \mathrm{cm}^{2}\right)\end{array}$ & $\begin{array}{c}\mathrm{e}_{\mathrm{x}}=\mathrm{e}_{\mathrm{y}} \\
(\mathrm{cm})\end{array}$ & Lifli Kumaş \\
\hline C1-0 & 6,466 & 4 & yok \\
C1-II & 5,772 & 4 & çift kat \\
C1-0-SF & 6,520 & 4 & yok \\
C1-II-SF & 6,759 & 4 & çift kat \\
C2-0 & 7,676 & 5 & yok \\
C2-II & 6,191 & 5 & çift kat \\
C2-0-SF & 6,437 & 5 & yok \\
C2-II-SF & 5,313 & 5 & çift kat \\
\hline
\end{tabular}

Hazırlanan kolon numuneler elemanların yük taşıma gücü kapasitelerinin, yük-deplasman eğrilerinin ve karbon lifli polimer malzeme sargısının kolon davranışı üzerine olan etkilerinin incelenmesi amaciyla seçilen eksantrisite değerlerinde yüklemeye tabi tutulmuştur.

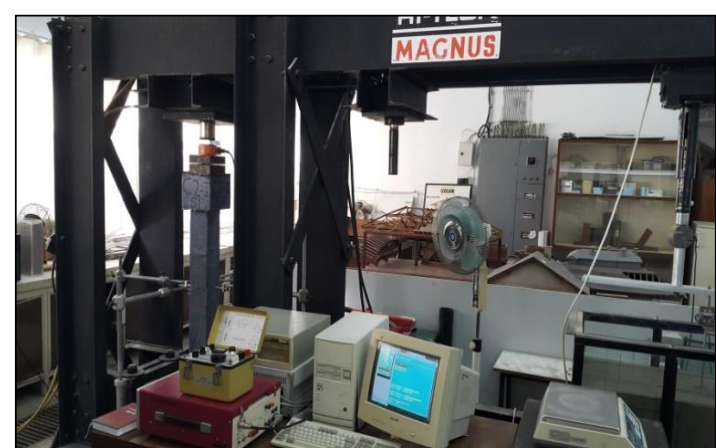

Şekil 3. Deney düzeneği

Deneylerde kullanılan düzenek Şekil 3'de verilmiş olup yanal deplasmanların ölçümü için lineer deplasman ölçerler, yükün kaydedilmesi için veri toplama sistemi, yükün numuneye eksenel yönde aktarımı için hidrolik silindir sistemi ve deney sırasında elemana etkiyen yükü tespit etmek için ise $500 \mathrm{kN}$ kapasiteli yük hücresi kullanılmıştır. Kullanılan yük hücresi ve deplasman ölçerler deneyden önce kalibre edilmiştir. Yük $1 \mathrm{kN} / \mathrm{sn}$ artımla numuneye verilmiş olup bu şekilde ortaya çıkacak yük-yanal deplasman eğrilerinin gerçek davranışı daha uygun ve düzgün bir şekilde yansıtması sağlanmıştır. Deney boyunca gerek yüklemedeki artım gerekse her iki eksen (x ve y) yönünde oluşan yanal deplasmanlar, veri toplama sistemi ile kaydedilmiştir. Çalışma kapsamında ele alınan kolon numunelerine ait deneysel sonuçlar Dündar, Ertürkmen ve Tokgöz (2015) tarafindan yapılan çalışmada detaylı olarak verilmektedir [10].

\subsection{Metot}

Bu çalışmada karbon lifli polimer sargılı sade veya lifli narin betonarme kolonların davranışlarının belirlenmesi için analitik bir yöntem önerilmiştir. $\mathrm{Bu}$ yöntem iki eksenli eğilme ve eksenel yüke maruz kolonlar için Tokgöz, Dündar ve Tanrıkulu (2008) tarafından geliştirilen programın, karbon lifli polimer sargili betonarme kolonlara uygun olarak yeniden düzenlenmesi sonucu ortaya çıkmıştır. Önerilen yöntemde, beton basınç bölgesi bu bölgede oluşan gerilmelerin hesaplanabilmesi için küçük elemanlara ayrılmıştır. Karbon lifli polimer malzemenin herhangi bir basınç kuvvetini karşılamadığı ve sadece boyuna doğrultuda 
oluşacak çekme kuvvetinin taşınmasına katkı sağladığı kabul edilmiştir. Bu nedenle karbon lifli malzeme, çekme bölgesinde de küçük elemanlara ayrılarak malzemede oluşan çekme gerilmeleri belirlenmiştir.

Önerilen analiz yönteminde yapılan varsayımlar: (1) eğilmeden önce düzlem olan kesitler, eğilmeden sonrada düzlem kalırlar. (2) malzemenin doğrusal olmayan davranışı esas alınır. (3) beton basınç bölgesi için literatürde mevcut sarg1lı ve sargısız beton gerilme-şekil değiştirme modelleri kullanılmıştır. (4) çelik için malzemenin elasto-plastik davranışını göz önüne alan gerilme-şekil değiştirme ilişkisi kullanılır. (5) betonun çekme dayanımına katkısı ihmal edilir. (6) sünme ve büzülme etkisi ihmal edilip beton, çelik ve CFRP malzemesi arasında tam bir aderans olduğu kabul edilmiştir. (7) eksenel ve kesme deformasyonları ihmal edilmiştir.

Analizlerde kullanılan malzemelere yönelik gerilme-birim deformasyon eğrileri Şekil 4 (ad)'de görülmektedir. CFRP malzemesi için malzeme davranışının kopma anına kadar lineer elastik olduğunu varsayan, donatı çeliği için elasto-plastik davranışı esas alan gerilme-birim deformasyon modelleri kullanılmıştır. Sargısız çelik lifsiz beton için Hognestad (1955) tarafından önerilen ve literatürde Hognestad Modeli olarak bilinen beton modeli dikkate alınırken; sargısız çelik lifli beton için Hsu ve Hsu (1994) tarafindan, sargılı beton için ise Punurai ve Hsu (2013) tarafından önerilen gerilme-birim deformasyon modelleri kullanılmıştır. Şekil 4 (a)'da verilen CFRP malzemesine ait gerilme şekil değiştirme diyagramında $\sigma_{\mathrm{f}}$ ve $\varepsilon_{\mathrm{f}}$ CFRP' nin gerilme ve şekil değiştirme değerleri olup; $\mathrm{f}_{\mathrm{fu}}$ ve $\varepsilon_{\mathrm{fu}}$ malzemeye ait maksimum gerilme ve şekil değiştirme değerleridir.

$$
\sigma_{f}=E_{f} \varepsilon_{f} \leq f_{f u} \quad 0 \leq \varepsilon_{f} \leq \varepsilon_{f u}
$$

Burada $E_{f}$ malzemeye ait elastisite modülü olup aşağıdaki ifade ile hesaplanmaktadır.

$$
E_{f}=\frac{f_{f u}}{\varepsilon_{f u}}
$$

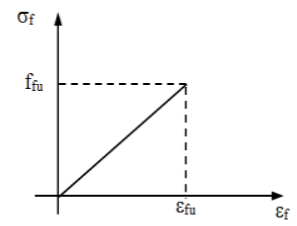

(a) CFRP

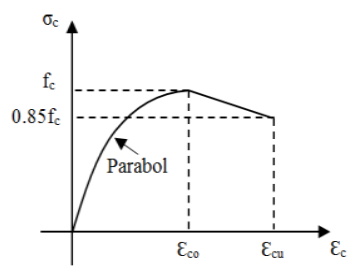

(c) Sargısız çelik lifsiz beton


Şekil 4 (a-d). CFRP, çelik, sargısız ve sargılı beton gerilme-şekil değiştirme eğrileri

Şekil 4 (b)'de çelik için verilen gerilme şekil değiştirme diyagramı malzemenin elasto-plastik davranışını temel almakta olup diyagramda görülen $\sigma_{\mathrm{s}}$ ve $\varepsilon_{\mathrm{s}}$ donatı çeliğinin gerilme ve şekil değiştirme değerleri olup; $f_{y}$ ve $E_{s}$ sirasıyla malzemeye ait akma dayanımı ve elastisite modülü değerleridir.

$$
\sigma_{s}=E_{s} \varepsilon_{s} \leq f_{y}
$$

Şekil 4 (c)'de sargısız numuneler için beton basınç bölgesinin tanımında kullanılan Hognestad modeli yer almaktadır. Modelde, betonun $(\sigma-\varepsilon)$ ilişkisi tanımlanırken $(\sigma-\varepsilon)$ ilişkisinin, eğrinin tepe noktasına kadar ikinci dereceden parabol olduğu, tepe noktasından sonraki azalan kısmının ise doğrusal olduğu varsayılmıştır. Modelde maksimum gerilmenin genelde beton silindir basınç dayanımının \%85'i olduğu kabul edilmiştir $\left(\mathrm{f}_{\mathrm{c}}=0,85 \mathrm{f}_{\mathrm{ck}}\right)$. Maksimum gerilmeye karşılık gelen birim kısalma değeri, $\varepsilon_{c o}=2 \mathrm{f}_{\mathrm{c}} / \mathrm{E}_{\mathrm{c}}$ olarak verilmiş ise de bu değer, basit bir yaklaşımla 0,002 olarak da alınabilmektedir. Kırılmaya karşılık gelen maksimum birim deformasyon değeri $\varepsilon_{\mathrm{cu}}=0,0038$ olarak kabul edilmektedir. Betonun elastisite modülü için ise (4) denklemi önerilmektedir.

$\mathrm{E}_{c}=\tan \alpha=12680+460 f_{c}(\mathrm{MPa})$ 
Modelde yer alan parabolik ve doğrusal kısmı ifade eden denklemler sirasiyla (5) ve (6) ifadelerinde yer almaktadır.

$$
\begin{aligned}
& \sigma_{c}=f_{c}\left[\frac{2 \varepsilon_{c}}{\varepsilon_{c o}}-\left(\frac{\varepsilon_{c}}{\varepsilon_{c o}}\right)^{2}\right] \\
& \sigma_{c}=f_{c}\left[1-0,15\left(\frac{\varepsilon_{c}-\varepsilon_{c o}}{\varepsilon_{c u}-\varepsilon_{c o}}\right)\right]
\end{aligned}
$$

Burada $\mathrm{f}_{\mathrm{c}}$ beton basınç dayanımını; $\varepsilon_{\mathrm{co}}$ maksimum gerilmeye karşılık gelen birim kısalmayı; $\varepsilon_{\mathrm{cu}}$ kırılma anındaki birim kısalmayı ve $\varepsilon_{\mathrm{c}}$ betondaki birim kısalmayı simgelemektedir.

Yapılan analizlerde sargısız çelik lifli numuneler için ise Hsu ve Hsu (1994) tarafından tanımlanan ve aşağıda denklemleri verilen gerilme-birim deformasyon ilişkisi kullanılmıştır.

$$
\sigma_{c}=\left[\frac{n_{1} \beta\left(\frac{\varepsilon_{c}}{\varepsilon_{0}}\right)}{n_{1} \beta-1+\left(\frac{\varepsilon_{c}}{\varepsilon_{0}}\right)^{n_{1} \beta}}\right] f_{c}
$$

Burada; $\quad\left(0 \leq \frac{\varepsilon_{c}}{\varepsilon_{0}} \leq x_{d}\right)$ olmalidir.

$\sigma_{c}=0,6 \exp \left[-0,7\left(\frac{\varepsilon_{c}}{\varepsilon_{0}}-x_{d}\right)^{0.8}\right] f_{c}$

Burada; $\quad\left(x_{d} \leq \frac{\varepsilon_{c}}{\varepsilon_{0}}\right)$ olmalıdır.

İfadelerde yer alan $\mathrm{n}_{1}$ ve $\beta$, malzeme parametreleri olup $\mathrm{n}_{1}$, malzeme dayanımına; $\beta$ ise gerilme-birim deformasyon eğrisinin şekline bağlıdır. Değerleri karışımda bulunan çelik lif miktarının hacimsel oranına göre değişmekte olan bu parametrelere ait kullanılan ifadeler ise Hsu ve Hsu (1994) tarafindan yapılan çalışmada detaylı olarak verilmektedir.

Yine yukarıda belirtilen denklemlerde yer alan $\sigma_{\mathrm{c}}$ değeri, beton basınç gerilmesini, $f_{c}$ değeri ise maksimum beton basınç gerilmesine karşılık gelen gerilmeyi simgelemektedir. Bununla birlikte, $\varepsilon_{0}$ maksimum gerilmeye karşılık gelen birim kısalmanın değerini, $\mathrm{x}_{\mathrm{d}}$ ise eğrinin azalan kısmını temsil eden bölümünde $0.6 \mathrm{f}_{\mathrm{c}}$ gerilmesine karşılık gelen birim kısalma değerini temsil etmektedir.

Şekil 4 (d)'de sargilı beton için verilen gerilme şekil değiştirme modelinde eğriler farklı eğime sahip iki artan doğrunun birleşmesi ile temsil edilmiş olup burada $\sigma_{\mathrm{c}}$ ve $\varepsilon_{\mathrm{c}}$ sırasıyla, CFRP sargılı betonun gerilme ve birim deformasyon değerleridir. $E_{1}$ ve $E_{2}$ ifadeleri ise verilen bu iki artan doğruya ait eğim yani elastisite modülü değerleridir. $f_{0}$ ikinci doğruya ait başlangıç gerilmesi olup bu noktadan itibaren oluşan gerilmeler plastik haldeki gerilmelerdir. $\mathrm{n}$ ise şekil faktörünü ifade etmektedir. Ayrıca $\varepsilon_{\mathrm{cu}}$ lifte oluşacak olan maksimum şekil değiştirmeyi, $\mathrm{f}_{\mathrm{cu}}$ ise CFRP sargilı betonda oluşacak olan maksimum gerilmeyi temsil etmektedir.

CFRP sarg1lı betonun gerilme-birim deformasyon davranışını belirleyen ifade Punurai ve Hsu (2013) tarafindan önerilen (9) denkleminde yer almaktadir.

$$
\sigma_{c}=\frac{\left(E_{1}-E_{2}\right) \varepsilon_{c}}{\left[1+\left(\frac{\left(E_{1}-E_{2}\right) \varepsilon_{c}}{f_{o}}\right)^{n}\right]^{1 / n}}+E_{2} \varepsilon_{c}
$$

$\mathrm{Bu}$ ifadede görülen ilk doğrunun eğimi olan $\mathrm{E}_{1}$ ifadesi ACI 318-08 (2008) tarafından önerilen denklem (10) kullanılarak hesaplanmaktadır.

$$
E_{1}=4730 \sqrt{f_{c}}
$$

Yine verilen ifadede yer alan ve ikinci doğrunun eğimi olan $E_{2}$ denklem (11)'deki ifade kullanılarak hesaplanmaktadir. Bu ifadede yer alan $\mathrm{E}_{\mathrm{f}} \mathrm{CFRP}$ kumaşının kuru haldeki etkili elastisite modülü 


$$
E_{2}=189,21 f_{c}^{0.2}+1.345 \frac{E_{f} t_{f}}{D}
$$

değeridir; $t_{f}$ CFRP kumaşının kalınlığı; D ise göbek betonun çapıdır.

$\mathrm{f}_{0}$ ikinci doğruya ait başlangıç gerilmesi olup denklem (12) ile hesaplanmaktadır.

$\mathrm{f}_{\mathrm{o}}=0,85 \mathrm{f}_{\mathrm{c}}+1.9 \mathrm{f}_{\mathrm{r}}+6,89$

Burada $f_{r}$ CFRP kumaşının sargılama basıncı olup denklem (13) ile elde edilmektedir.

$$
f_{r}=\frac{2 f_{f} t_{f}}{D}
$$

Burada yer alan $\mathrm{f}_{\mathrm{f}}$ ise halka gerilmesidir.

CFRP sarg1l betona ait maksimum gerilme olan $\left(f_{\mathrm{cu}}\right)$ ve ona karşıllk gelen birim deformasyon $\left(\varepsilon_{\mathrm{cu}}\right)$ değerleri ise aşağıda verilen ifadelerle elde edilebilmektedir:

$$
\begin{gathered}
\mathrm{f}_{\mathrm{cu}}=\mathrm{f}_{\mathrm{c}}+6,14 \mathrm{f}_{\mathrm{r}}^{0.75} \\
\varepsilon_{c u}=\frac{f_{c u}-f_{o}}{E_{2}}
\end{gathered}
$$

\section{ANALITIK YÖNTEM FORMÜLASYONLAR}

İki eksenli eğilme ve eksenel basınca maruz CFRP sargılı kolon kesiti ve birim deformasyon dağılımı Şekil 5'de görülmektedir.

Analizde karbon fiber polimer malzeme çekme bölgesinde, beton malzeme basınç bölgesinde tarafsız eksen konumuna paralel olarak şeritlere ayrılmaktadır. Bu şeritlerin ağırlık merkezindeki birim deformasyon değerleri Denklem (16) yardımıyla hesaplanmaktadır. Hesaplanan birim deformasyonlara karşıllı gelen gerilmeler her bir malzemenin gerilme-birim deformasyon modelinden belirlenmektedir.

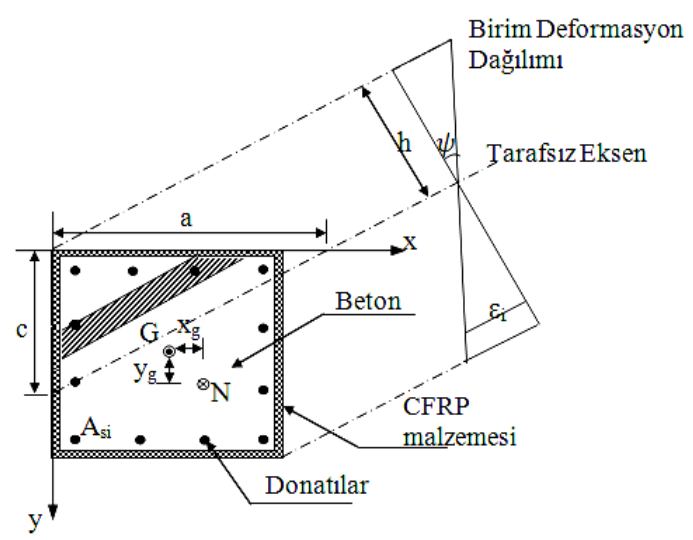

Şekil 5. CFRP sargılı kolon kesiti ve birim deformasyon dağılımı

$\varepsilon_{i}=\varepsilon_{c u}\left[\left(\frac{y_{i}}{c}+\frac{x_{i}}{a}\right)-1\right]$

Burada a ve c ifadeleri sirasiyla $x-y$ eksenlerinin orijin noktasından tarafsiz eksene olan mesafeleridir. $\varepsilon_{\mathrm{cu}}$ betonda oluşan maksimum birim deformasyon değeridir. Oluşacak eğrilik aşağıdaki ifade ile saptanmaktadir.

$\psi=\frac{\varepsilon_{c}}{h}$

Burada $\varepsilon_{\mathrm{c}}$ betonda oluşan birim deformasyon değeri olup $\mathrm{h}$ maksimum basınç lifi ile tarafsız eksen arasındaki mesafedir.

CFRP sargılı kesitin içinde oluşan eksenel kuvvet ve kuvvetin uygulandığ 1 eksantrisite nedeniyle kesitin $\mathrm{x}$ ve $\mathrm{y}$ eksenleri yönünde oluşan eğilme momenti değerleri statik olarak diştan uygulanan eksenel kuvvet ve yükün uygulandığ1 eksantrisiteden doğan eğilme momentlerine eşit olacaktır. Kesitin içinde oluşacak olan eksenel kuvvet ve momentler betonda, donatı çeliğinde ve CFRP kumaşında meydana gelen kuvvet, gerilme ve şekil değiştirmelerin ortak etkisiyle aşağıda verilen denge denklemleri kullanılarak hesaplanacaktır. 


$$
\begin{aligned}
& N=\sum A_{c} \sigma_{c}+\sum A_{s} \sigma_{s}+\sum A_{f p} \sigma_{f p} \\
& M_{x}=\sum A_{c} \sigma_{c} y_{c}+\sum A_{s} \sigma_{s} y_{s}+\sum A_{f p} \sigma_{f p} y_{f p} \\
& M_{y}=\sum A_{c} \sigma_{c} x_{c}+\sum A_{s} \sigma_{s} x_{s}+\sum A_{f p} \sigma_{f p} x_{f p}
\end{aligned}
$$

Burada $A_{c}, A_{s}$ ve $A_{f p}$ sirasıyla betonun, çeliğin ve CFRP kumaşının kesit alanlarıdır. $\sigma_{\mathrm{c}}, \sigma_{\mathrm{s}}$ ve $\sigma_{\mathrm{fp}}$ sırasıyla betonun, çeliğin ve CFRP kumaşının gerilme değerleridir. $\left(\mathrm{x}_{\mathrm{c}}, \mathrm{y}_{\mathrm{c}}\right),\left(\mathrm{x}_{\mathrm{s}}, \mathrm{y}_{\mathrm{s}}\right)$ ve $\left(\mathrm{x}_{\mathrm{fp}}, \mathrm{y}_{\mathrm{fp}}\right)$ yine sırasılyla betonun, donatı çeliğinin ve CFRP kumaşının kesit ağırlı merkezine olan mesafeleridir. CFRP kumaşında meydana gelecek kuvvetler kumaşın elemana boyuna yönde uygulanması hali için hesaba alınmıştır.

Sargısız ve sargılı kolon numunelerinin analizinde, oluşacak olan eksenel yük ve moment taşıma kapasitesi değerlerinin hesabı için narinlik etkisini göz önüne alan ACI-318 yönetmeliği tarafindan önerilen Moment Büyütme Yöntemi kullanılmıştır.

\section{MOMENT BÜYÜTME YÖNTEMI}

Betonarme yapilarda mevcut bulunan kolon elemanlarının kesit boyutları, boylarına oranla küçük olduğundan kolonlar genelde narin eleman olarak davranırlar. Eğilme etkisine maruz narin bir kolonda, yer değiştirmeden dolayı ilave bir moment meydana gelmektedir. İkinci mertebe momenti olarak adlandırılan bu ilave moment $\mathrm{N}(\Delta)$ mertebesindedir ve genellikle kolon ortasinda maksimum olmaktadır (Şekil 6).

İkinci mertebe momentler çoğunlukla ihmal edilemeyecek boyutta olabilmektedir. Bu nedenle hesaplara dahil edilmeleri gerekir. $\mathrm{Bu}$ amaçla kolonlarda meydana gelen yer değiştirme değerlerinin de doğru olarak saptanması önemli olmaktadır. Ancak, kolonların karmaşık sınır koşullarına sahip olması, betonarmenin doğrusalelastik olmayan bir malzeme olması, davranışın zamana ve yük geçmişine bağlı olması gibi nedenlerden dolayı yer değiştirmelerin kesin olarak elde edilmesi mümkün olamamaktadır. Bu



Şekil 6. Eksantrik yük altında kolonda oluşan deplasman

nedenle hesaplarda bir takım kabuller yaparak sonuca gidilmektedir.

$M_{\max }=N(e)+N(\Delta)$

Kolonlarda narinlik etkisini hesaplara katmak için ACI yönetmeliğinde öngörülen ve TS 500-2000 tarafindan da kabul edilen "Moment Büyütme Yöntemi” kullanılmaktadır. Yöntemin kullanılabilmesi için narinlik oranının denklem (22)'de verilen ifadeyi sağlaması gerekmektedir.

$$
\frac{L_{k}}{i} \leq 100 \quad\left(i=\sqrt{\frac{I}{A}}\right)
$$

Burada $\mathrm{L}_{\mathrm{k}}$ kolon etkili boyunu; $\mathrm{i}$ ise kesit atalet yarıçapını göstermektedir. Bu yöntemde narinlik etkisinden meydana gelen ikinci mertebe momentlerinin de dahil edildiği moment değeri $\left(\mathrm{M}_{\max }\right)$, birinci mertebe momentinin $\mathrm{N}(\mathrm{e})$, moment büyütme katsayısı ( $\delta)$ ile çarpılmasılyla elde edilmektedir.

$$
\begin{aligned}
& \delta=\frac{C_{m}}{1-1,33 \frac{N_{u}}{N_{c r}}} \geq 1.0 \\
& C_{m}=0,6+0,4 \frac{M_{u 1}}{M_{u 2}} \geq 0,4 \quad M_{u 1} \leq M_{u 2}
\end{aligned}
$$


İki ucu mafsallı kolonlarda $\mathrm{C}_{\mathrm{m}}=1,0$ alınmaktadır. $\mathrm{N}_{\text {cr }}$ kolon burkulma yükü olup aşağıdaki ifade ile tanımlanmaktadır.

$$
N_{c r}=\frac{\pi^{2} E I}{(k L)^{2}}
$$

Burada (kL) kolon etkili boyu; EI ise kolonun etkili eğilme rijitliğini göstermektedir. Betonarme kolonlar için eğilme rijitliği, TS 500-2000 tarafından önerilen aşağıdaki ifade ile ele alınmaktadır.

$$
E I=\frac{0,4 E_{c} I_{c}}{1+\beta_{d}}
$$

Burada $\mathrm{E}_{\mathrm{c}}$ beton elastisite modülünü, $\mathrm{I}_{\mathrm{c}}$ kesit atalet momentini ve $\beta_{\mathrm{d}}$ sünme oranını göstermektedir. Kısa süreli yüklemeye maruz elemanlarda $\beta_{\mathrm{d}}=0$ alınmaktadır.

Eğik eğilmeye maruz betonarme kolonların narinlik hesabında moment büyütme çarpanı $\left(\delta_{\mathrm{x}}, \delta_{\mathrm{y}}\right)$ iki yönde ayrı ayrı hesaplanarak ilgili momentlerle çarpılmak suretiyle hesaplara yansitılmaktadir.

$$
M_{u x}=\delta_{x} N_{u} e_{y} \quad M_{u y}=\delta_{y} N_{u} e_{x}
$$

Narinlik hesabında, analiz ve tasarımda oluşturulan denge denklemleri sağlanıncaya kadar her iterasyonda iki yönde moment büyütme çarpanı $\left(\delta_{\mathrm{x}}, \delta_{\mathrm{y}}\right)$ değeri hesaplanarak işlemlere katılmaktadır.

\section{ARAȘTIRMA BULGULARI}

Yapılan bu çalışma kapsamında, iki eksenli eğilme ve eksenel basınç altında deneysel olarak test edilen kolonlar, narinlik hesabinda Moment Büyütme Yöntemi göz önüne alınarak geliştirilmiş olan bilgisayar programı kullanılarak analiz edilmiştir. Analizde beton basınç bölgesi için sargısız çelik lifsiz numuneler için Hognestad modeli (1955), sargısız çelik lifli numuneler için Hsu ve Hsu (1994) tarafindan önerilen model ve sarg1lı numuneler için ise Punurai ve Hsu (2013) tarafindan önerilen sargilı beton gerilme-birim deformasyon modeli kullanılmıştır.

Analiz sonucunda elde edilen moment ve eksenel yük taşıma gücü değerleri, deneysel olarak elde edilen değerler ile karşılaştırmalı olarak Çizelge 3'de verilmiştir.

Çizelge 3. Kolon numunelerine ait deneysel ve analitik taşıma gücü değerleri

\begin{tabular}{lcccc}
\hline Numune & $\begin{array}{c}\mathrm{N}_{\mathrm{d}} \\
(\mathrm{kN})\end{array}$ & $\begin{array}{c}\mathrm{N}_{\text {test }} \\
(\mathrm{kN})\end{array}$ & $\begin{array}{c}\mathrm{M}_{\mathrm{x}} \& \mathrm{M}_{\mathrm{y}} \\
(\mathrm{kNcm})\end{array}$ & $\begin{array}{c}\mathrm{N}_{\mathrm{d}} / \\
\mathrm{N}_{\text {test }}\end{array}$ \\
\hline C1-0 & 199,03 & 203 & 932,57 & 0,980 \\
C1-II & 385,31 & 350 & 1531,10 & 1,100 \\
C1-0-SF & 198,62 & 220 & 929,63 & 0,903 \\
C1-II-SF & 425,24 & 365 & 1699,47 & 1,165 \\
C2-0 & 165,72 & 155 & 932,88 & 1,069 \\
C2-II & 333,95 & 283 & 1669,52 & 1,180 \\
C2-0-SF & 150,02 & 162 & 843,35 & 0,926 \\
C2-II-SF & 305,29 & 267 & 1529,92 & 1,143 \\
\hline
\end{tabular}

C1-0, C1-II, C1-II-SF ve C2-0-SF numunelerine ait deneysel ve analitik olarak elde edilen yük-deplasman eğrileri ise karşılaştırmalı olarak Şekil 6 (a-d)'de sunulmuştur.

\section{TARTIŞMA VE SONUÇLAR}

Sunulan çalışmada lifli ve lifsiz, çift kat CFRP sarg1lı ve sargısız, yüksek dayanımlı beton kullanılarak hazırlanmış 8 adet kare kesitli kolon numunesi, iki eksenli eğilme ve eksenel basınç altında deneye tabi tutulmuş ve analiz için analitik bir yöntem geliştirilmiştir.

Yapılan deneylerde lifsiz karışıma sahip olan C1-0 ve C2-0 olarak adlandırılan numuneler, yüksek dayanımlı beton kullanılarak hazırlandıkları için oldukça gevrek bir davranış sergilemişlerdir. C1-0SF ve C2-0-SF olarak adlandırılan lifli numuneler ise yük etkisinde lifsiz olan numunelere kıyasla çok daha fazla deformasyon yapma özelliği göstermişlerdir. $\mathrm{Bu}$ da yüksek dayanımlı betona ilave edilen çelik lifin, betonun sünekliğini önemli ölçüde arttırdığı sonucunu doğrulamaktadır [13]. 




(a)

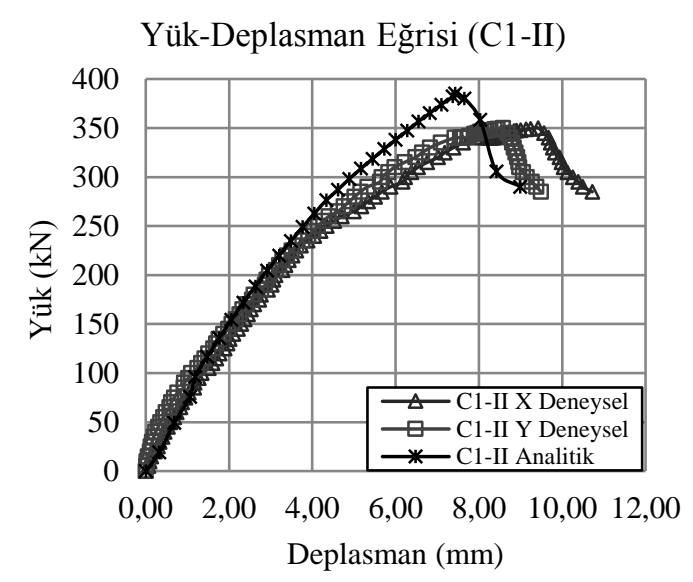

(b)

\section{Yük-Deplasman Eğrisi (C1-II-SF)}

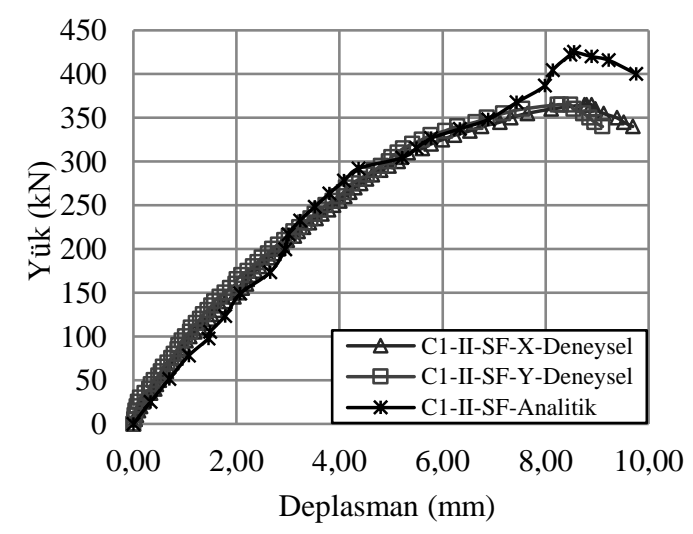

(c)

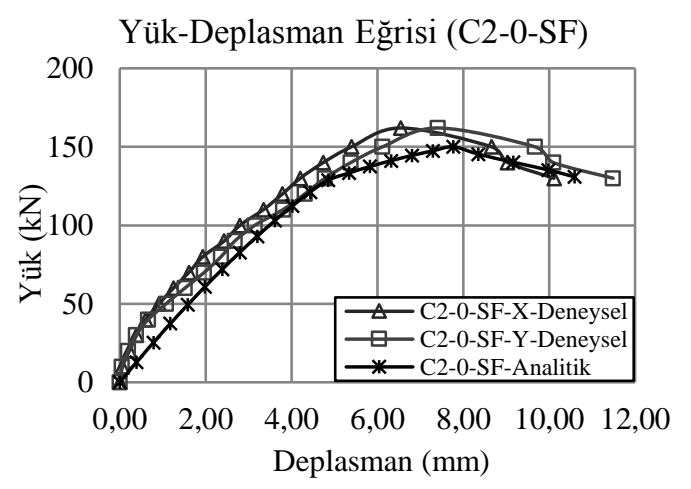

(d)

Şekil 6 (a-d). Bazı numunelere ait karşılaştırmalı yük-deplasman eğrileri

Kolonlarda meydana gelen göçme veya çatlamaların genelde numunenin orta kısımlarında meydana geldiği gözlenmiştir. CFRP malzemesi ile sarılan gerek lifli gerek lifsiz kolon numunelerinde, sarg1 malzemesinde enine yönde bulunan liflerin numunelerin yanal rijitliğini arttırdığı görülmüștür. Test edilen kolonlarda önce kolonun çekme bölgesinde, çekme çatlaklarının oluşumu gözlenmiş sonra basinç bölgesinde betonun kırılması ile numunenin taşıma gücüne eriștiği belirlenmiştir. Çift yönlü lif içeren CFRP sargısının, eğilme çatlağı oluşumunu ertelediği sonucuna varılmıştır. Moment Büyütme Yöntemi kullanılarak yapılan analizler sonucunda elde edilen taşıma gücü değerlerinin deneysel değerlerle uyumlu olduğu görülmüştür.

Yapılan deneylerden ve analizlerden elde edilen sonuçlara göre, eksantrik yüklemeye maruz kalan yüksek dayanımlı betonarme kolonların gevrek kırılmasını önlemek ve sünek davranmasını sağlamak için; bu kolonlara çelik lif ilave edilmesi, aynı zamanda burkulmaları azaltmak, süneklik ve dayanımı arttırmak için de CFRP ile sarılması önerilmektedir.

\section{TEŞEKKÜR}

$\mathrm{Bu}$ çalışma Çukurova Üniversitesi Bilimsel Araştırma Projeleri Birimi tarafindan desteklenmiştir (Proje no: MMF2013D22). 


\section{KAYNAKLAR}

1. Dundar C., Tokgoz S., Tanrikulu A.K., Baran T., 2008. Behaviour of Reinforced and Concrete-Encased Composite Columns Subjected to Biaxial Bending and Axial Load, Building and Environment, 43(6): 1109-20.

2. Mirmiran, A., Shahawy, M., 1997. Behavior of Concrete Columns Confined by Fiber Composite, Journal of Structural Engineering ASCE, 123(5):583-590.

3. Toutanji, H., Balaguru, P., 1998. Durability Characteristics of Concrete Columns Wrapped with FRP Tow Sheets, Journal of Materials Civil Engineering ASCE, 10(1):52-57.

4. Teng, J.G., Lam, L., 2002. Compressive Behavior of CFRP-Confined Elliptical Concrete Columns, Journal of Structural Engineering ASCE, 128(12):1535-1543.

5. Samaan, M., Mirmiran, A., Shahawy, M., 1998. Model of Concrete Confined by Fiber Composites, Journal of Structural Engineering ASCE, 124(9):1025-1031.

6. Hadi, M.N.S., 2006. Behaviour of FRP Wrapped Normal Strength Concrete Columns under Eccentric Loading, Composite Structures, 72(4):503-511.

7. Zaki, M.K., 2011. Investigation of FRP Strengthened Circular Columns under Biaxial Bending, Engineering Structures, 33:1666-1679.

8. Vincent, T., Ozbakkaloglu, T., 2013. Influence of Fiber Orientation and Specimen end Condition on Axial Compressive Behavior of FRP-Confined Concrete, Construction and Building Materials, 47:814-826.

9. Punurai, W., Hsu, C.T.T., Punurai, S., Chen, J., 2013. Biaxially Loaded RC Slender Columns Strengthened by CFRP composite Fabrics, Engineering Structures, 46:311-321.

10. Dundar C., Erturkmen D., Tokgoz S., 2015. Studies on Carbon Fiber Polymer Confined Slender Plain and Steel Fiber Reinforced Concrete Columns, Engineering Structures, 102:31-39.
11. Hognestad, E., Hanson, N.W., Mchenry, D., 1955. Concrete Stress Distribution in Ultimate Stress Design, ACI Journal, 27(4), 455-479.

12. Hsu L.S.M., Hsu C.T.T.,1994. Stress-Strain Behavior of Steel Fiber High-Strength Concrete under Compression, ACI Structural Journal, 91(4):448-457.

13. Tokgoz, S., 2009. Effects of Steel Fiber Addition on the Behaviour of Biaxially Loaded High Strength Concrete Columns, Materials and Structures, 42(8):1125-1138.

14. ACI 318, 2008. Building Code Requirements for Structural Concrete, Detroit (MI), American Concrete Institute. 
